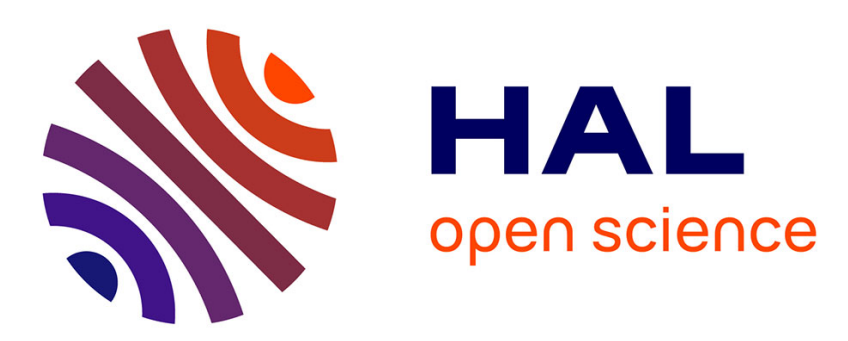

\title{
Experimental evaluation of live cage-traps for black-billed magpies management in Spain
}

Francisco Díaz-Ruiz, Jesús T. García, Lorenzo Pérez-Rodríguez, Pablo Ferreras

\section{- To cite this version:}

Francisco Díaz-Ruiz, Jesús T. García, Lorenzo Pérez-Rodríguez, Pablo Ferreras. Experimental evaluation of live cage-traps for black-billed magpies management in Spain. European Journal of Wildlife Research, 2009, 56 (3), pp.239-248. 10.1007/s10344-009-0310-3 . hal-00535244

\section{HAL Id: hal-00535244 https://hal.science/hal-00535244}

Submitted on 11 Nov 2010

HAL is a multi-disciplinary open access archive for the deposit and dissemination of scientific research documents, whether they are published or not. The documents may come from teaching and research institutions in France or abroad, or from public or private research centers.
L'archive ouverte pluridisciplinaire HAL, est destinée au dépôt et à la diffusion de documents scientifiques de niveau recherche, publiés ou non, émanant des établissements d'enseignement et de recherche français ou étrangers, des laboratoires publics ou privés. 


\title{
Experimental evaluation of live cage-traps for black-billed magpies Pica pica management in Spain
}

\author{
Francisco Díaz-Ruiz • Jesús T. García • \\ Lorenzo Pérez-Rodríguez • Pablo Ferreras
}

Received: 26 November 2008 / Revised: 30 June 2009 / Accepted: 27 July 2009 / Published online: 20 August 2009

(C) Springer-Verlag 2009

\begin{abstract}
Black-billed magpies (Pica pica) are considered as a nest predator of game and non-game birds in Europe. In rural areas of Spain magpie control is commonly used as a management tool in small game hunting estates. Cagetraps with a magpie as a decoy are the legal method most commonly used for controlling magpies in Spain although its performance has not yet been experimentally tested. We evaluated the selectivity, efficiency, and the effect of different factors on capture rate of these traps for magpie control and determine the effect of magpie removal on magpie density. Only four out of 197 captures corresponded to non-target species, which were released unharmed. Since the release of non-target captures depends on the daily checking of the trap and the trapper commitment, in order to guarantee the efficiency and selectivity of this method traps should be revised daily by full time, qualified trappers. The efficiency of this method is high during the breeding season, reducing magpie density in the area where the control is performed. Highest capture rates were obtained in the first days after cage-traps setting. Neither the gender nor the origin (local or foreign) of the decoy
\end{abstract}

Communicated by C. Gortázar

F. Díaz-Ruiz ·J. T. García $\cdot$ L. Pérez-Rodríguez $\cdot$ P. Ferreras $(\bowtie)$ Instituto de Investigación en Recursos Cinegéticos, IREC (CSIC-UCLM-JCCM),

Ronda de Toledo $\mathrm{s} / \mathrm{n}$,

13071 Ciudad Real, Spain

e-mail: pablo.ferreras@uclm.es

Present Address:

L. Pérez-Rodríguez

School of Biological Sciences, University of Aberdeen,

Aberdeen AB24 2TZ, UK significantly affected the capture rate. Among male decoys, experimentally increased testosterone levels did not increase capture rates. According to our results, the tested cage-traps with a living decoy could be employed as an efficient and selective method for magpie population management in Spain, when used by full time, qualified trappers.

Keywords Cage-traps · Capture rate · Black-billed magpie Selectivity $\cdot$ Predator management

\section{Introduction}

The effect of predators on species with high socioeconomic value frequently causes conflicts among social stakeholders (Thirgood et al. 2000; Sillero-Zubiri and Laurenson 2001). Such conflicts have often caused the persecution of predators through illegal and non-selective methods (Delibes-Mateos 2006), causing negative impacts on wildlife conservation (Villafuerte et al. 1998).

Hunting of red-legged partridges (Alectoris rufa) is an activity of economic interest in many rural areas of central and southern Spain (Bernabeu 2000). Predation is regarded in many of these areas as one of the main causes of the partridge populations decline (Vargas 2002). Among the predators of red-legged partridges, corvids are assumed to have high impact on partridge nests (Yanes et al. 1998) and, consequently, they have been traditionally controlled. In these areas, the black-billed magpie (Pica pica) is the most abundant corvid species, and magpie control is commonly employed in small game hunting estates in Spain (Otero 1995).

The black-billed magpie is a generalist species, living in a wide range of habitats (Birkhead 1991). It feeds on a 
broad spectrum of food types: seeds, fruits, ground invertebrates, carrion, and small vertebrates. Eggs form only a small proportion of the magpie diet (Birkhead 1991; Martínez et al. 1992), and the impact of magpies on bird populations is still controversial (Gooch et al. 1991; Thomson et al. 1998; Chiron and Julliard 2007).

Some studies performed in Spain during the red-legged partridge breeding period suggested that most eggs consumed by magpies belong to red-legged partridges (77.8\%, Herranz 2000). According to artificial nest experiments, magpies may be locally the most important predator of redlegged partridge nests, (Blanco-Aguiar et al. 2001) and magpie abundance may be regionally the best indicator of nest predation probability (Ferreras et al. 2006). Population dynamics of partridges can be negatively affected by nest predation (Potts 1980), and hence in places where magpies reach high densities, their removal may increase the breeding success of red-legged partridges and other game bird species (Martínez de Castilla and Martínez 2004).

Black-billed magpies are in expansion in Europe since 1960 (Birkhead 1991) and a positive trend of $25 \%$ has been reported in Spain between 1995 and 2001 (SEO/BirdLife 2002). Effective management tools for abundant populations of magpies can be therefore necessary for alleviating their pressure on declining species such as red-legged partridges in circumstances where predation on nests is particularly high.

Many methods have been traditionally used in Spain for capturing magpies, including currently forbidden methods such as eagle owls (Bubo bubo) as decoys combined with mist nests (Wang and Trost 2000), glued branches (Boza 2002), or poisoned baits, the latter frequently used in Spain over the last decades (Hernandez and Margalida 2009) and legally prohibited since 1989 (Law 4/1989 on Conservation of Natural Areas and Flora and Wildlife) to be massive and non-selective methods.

Currently, the methods legally employed for capturing magpies include shooting in communal roosts or driven hunting, nest destruction, and cage-traps. Among these, cage-traps with a magpie as a decoy is the most commonly used method, likely due to their efficiency and their ease to operate. Gamekeepers, hunters, and manufacturers assure that cage-traps with a magpie as a decoy are an effective and selective method for reducing magpie density. Popular recommendations for increasing the capture rate based on non-systematic observations include using foreign magpies (i.e., magpies originating from an area different from the one in which cages are being used) as decoys, and using them throughout the magpie breeding season. Also, these popular recommendations suggest to use male birds as decoys, as it is expected that their more active territorial behavior, which is highly determined by testosterone levels (Wingfield et al. 1987), will be more effective in attracting conspecifics to traps. However, no experimental studies have tested these recommendations. On the other hand, conservationists claim that cage-traps aimed to capture magpies are often not selective and may negatively affect other species, particularly raptors, which enter into the traps trying to capture the decoy.

The objectives of the present study were (1) to assess the selectivity of cage-traps; (2) to evaluate the efficiency of cage-traps with a living decoy to capture black-billed magpies; (3) to determine the effect on the capture rate of several factors such as the gender and testosterone levels of decoys, the origin of decoys, the trapping season, and the permanence time of traps in the same place; and (4) to determine the effect of magpie removal on magpie density.

\section{Study area}

The study was carried out in two hunting estates located in Castilla-La Mancha (Central Spain) during spring and autumn 2006. Area 1 (960 ha) was placed in the province of Ciudad Real, within an agricultural-dominated landscape. Natural vegetation layers were primarily bushes and some trees associated to riparian areas. Hunting is an important activity in this area, where the main game species are the Iberian hare (Lepus granatensis), the wild rabbit (Oryctolagus cuniculus), and the red-legged partridge. Magpies were not systematically controlled before the study, although they were occasionally shot during the hunting season. Area 2 (547 ha), located in the province of Toledo, was also dominated by agricultural landscape, and bushes and some trees were associated with hedgerows. The main game species were the Iberian hare and the wild rabbit; the density of the red-legged partridge was low and hence it was not among the main game species. Magpies were not controlled in this study area prior to this study. Magpie density before the breeding season was similar in the two study areas (see below).

\section{Materials and methods}

\section{Magpie trapping}

We evaluated the efficiency of four different models of cage-traps commonly used in Spain for capturing magpies, all of them using a live magpie as decoy. Cage-traps have one central chamber for the decoy and several capture chambers around the decoy chamber, employing a guillotine-type door as capture system. Models 1-3 had four capture chambers, octagonal prism structure, and similar size (approximately $85 \times 85 \times 35 \mathrm{~cm}$, length $\times$ width $\times$ height; See Appendix). Model 4 had two capture chambers 
and rectangular prism structure (model $4,90 \times 30 \times 30 \mathrm{~cm}$, length $\times$ width $\times$ height; See Appendix). All cage-traps were made of metallic mesh of variable gauge, thick $(3 \mathrm{~mm})$ in model 1 , medium $(1.9 \mathrm{~mm})$ in model 3 , and light $(1 \mathrm{~mm})$ in models 2 and 4.

Cage-traps were located near magpie nests $(<50 \mathrm{~m})$. For this purpose, nests were searched previous to the spring trapping experiments (February-March). Magpie nests are easily found during this season because deciduous trees lack leaves; magpie nests are large, distinctive, and conspicuous (Birkhead 1991); and pairs are very active building and defending the nest. Traps were separated at least $50 \mathrm{~m}$ among them, and under tree or shrub shade to avoid sunstroke of the decoy and captured animals in the central hours of the day. All cage-traps were checked daily in the morning, all captures removed, and the decoy was provided with food and water ad libitum.

In order to compare the effect of different factors on traps performance we defined capture rate as the average number of magpies captured per day that a trap is operative (International Organization for Standardization 1999).

\section{Testosterone manipulation}

Testosterone causes aggressive and territorial behavior in male birds (Wingfield et al. 1987), which could affect the capture efficiency of decoys. For this reason, ten male decoys, sexed through molecular techniques from blood samples (Fridolfsson and Ellegren 1999), were experimentally provided with testosterone implants. Implants consisted in $10-\mathrm{mm}$ long silastic tubes (inner diameter of $1.47 \mathrm{~mm}$, outer diameter of $1.97 \mathrm{~mm}$ ) filled with crystallized testosterone (T-males; ICN Biomedicals, Irvine, CA, USA) or empty (C-males). These tubes were subcutaneously implanted in the dorsal zone between the wings (Blas et al. 2006). To assess the efficiency of testosterone implants in creating significant differences in testosterone levels between T-males and C-males, we collected $0.3 \mathrm{ml}$ of blood from the brachial vein of all birds before and 5 days after implantation. Blood samples were stored cold $\left(4^{\circ} \mathrm{C}\right)$ and centrifuged within $4 \mathrm{~h}$, and plasma was subsequently stored at $-80^{\circ} \mathrm{C}$ until testosterone quantification. Plasma testosterone concentration was measured using a commercially available testosterone enzyme immunoassay (Elisa Kit EIA-1559 from DRG Diagnostics, Marburg, Germany). Before implanting, $\mathrm{C}$ - and T-males did not differ in plasma testosterone levels ( $t$ test, $t=0.87, p=0.39$ ). However, after implanting, T-males showed higher testosterone levels than C-males (2.3 \pm 0.11 (SE) and $1.04 \pm 0.13(\mathrm{SE}) \mathrm{ng} / \mathrm{ml}$, respectively; $t$ test, $t=8.53, p<0.05$ ). Testosterone levels of T-males after implantation were within the range found in control birds or all birds before manipulation. Although testosterone levels where not measured again during the rest of the experiment, our previous experiences indicate that implants of this size are fully active during at least 50 days. In addition, the visual inspection of implants through the skin indicated that they were still active (i.e. they were partially filled with testosterone) during the whole extension of the experiment.

\section{Experimental design}

Four experiments were designed to test the effect of different factors on capture rate (Table 1). Experiments 1, 2 , and 4 consisted of $n(2-4)$ blocks or groups of traps of the same model. Each block included one trap of each treatment. For instance, each block in experiment 1 consisted of one trap with female decoy, one trap with Tmale decoy, and one trap with C-male decoy. Experiment 3 consisted in a single block of nine traps of models 1,2 , and 3 (all with four capture chambers). Traps belonging to one block were set in the same area separated at least $50 \mathrm{~m}$.

- Experiment 1 was performed during spring in Area 1, using three decoy types: females (F), control males $(\mathrm{CM})$, and males implanted with testosterone (TM). All decoys were from foreign origin. Fifteen cage-traps were installed and remained active for 13 days. The following variables were evaluated with this experiment: trap model, gender, and testosterone of decoy and days since trap placement. Moreover, the effect of magpie removals on magpie density was examined together with data from experiments 2 and 4.

Table 1 Summary of field experiments: variables evaluated, decoy gender and testosterone level ( $F$ female, $C M$ control male, $T M$ testosterone implanted male), decoy origin, area where the experiment was carried out, season, total number of traps employed, and duration (days) of the experiment

\begin{tabular}{|c|c|c|c|c|c|c|c|}
\hline Experiment & Variables & $\begin{array}{l}\text { Decoy gender } \\
\text { and testos. }\end{array}$ & Decoy origin & Study area & Season & $\mathrm{Nr}$ traps & $\begin{array}{l}\text { Duration } \\
\text { (days) }\end{array}$ \\
\hline Exp.1 & Gender and testosterone and trap model & $\mathrm{F}, \mathrm{CM}$, and $\mathrm{TM}$ & Foreign & Area 1 & Spring & 15 & 13 \\
\hline Exp.2 & Gender, origin and trap model & $\mathrm{F}$ and $\mathrm{CM}$ & Foreign and local & Area 1 & Spring & 16 & 10 \\
\hline Exp.3 & Season & $\mathrm{F}$ and $\mathrm{CM}$ & Local & Area 1 & Autumn & 9 & 20 \\
\hline Exp.4 & Gender and testosterone and trap model & $\mathrm{F}, \mathrm{CM}$, and $\mathrm{TM}$ & Foreign & Area 2 & Spring & 12 & 14 \\
\hline
\end{tabular}


Table 2 Non-target species susceptible of being captured in the traps that were observed in the traps vicinity during daily trap checking and along weekly linear transects in both study areas

\begin{tabular}{|c|c|c|c|c|}
\hline & \multicolumn{2}{|c|}{ Linear transects } & \multicolumn{2}{|c|}{ Trap vicinity } \\
\hline & Area 1 & Area 2 & Area 1 & Area 2 \\
\hline Circus sp. & 7 & 6 & 7 & 0 \\
\hline Buteo buteo & 6 & 13 & 4 & 1 \\
\hline Asio otus & 0 & 0 & 1 & 0 \\
\hline Milvus migrans & 6 & 0 & 0 & 0 \\
\hline Accipiter nisus & 2 & 0 & 0 & 0 \\
\hline Hieraaetus pennatus & 1 & 0 & 0 & 0 \\
\hline Corvus corone & 0 & 0 & 1 & 0 \\
\hline Corvus monedula & 36 & 108 & 0 & 0 \\
\hline Total length $(\mathrm{km})$ & 219 & 60 & & \\
\hline
\end{tabular}

- Experiment 2 was performed during spring in Area 1, using $\mathrm{F}$ and $\mathrm{CM}$ decoys with different origins, local (L) and foreign (F). Sixteen cage-traps were installed and remained active for 10 days. In this experiment we evaluated the following variables: trap model, gender and origin of decoys, and days since trap placement. Moreover, the effect of magpie removal on magpie density was examined together with data from experiments 1 and 4 .

- Experiment 3 was performed during autumn in Area 1, using $\mathrm{F}$ and $\mathrm{CM}$ decoys, all from local origin. We installed nine cage-traps that remain active for 20 days. This experiment was used for evaluating trapping season, together with experiments 1 and 2.

- Experiment 4 was performed during the spring season in Area 2, using three types of decoy: F, CM, and TM, all decoys from foreign origin. We installed 12 cagetraps that remained active during 14 days. In this experiment we evaluated trap model, the gender, and testosterone of decoy. Moreover, the effect of magpie removal on magpie density was examined together with data from experiments 1 and 2.

\section{Handling of captures}

Captured animals were examined for possible trap-related injuries. Non-target species were checked for injuries and
Table 4 Summary of results of the mixed model of capture rate including time since installation and decoy origin (data from spring in study areas 1 and 2)

\begin{tabular}{lccc}
\hline Effect & DF & $F$ value & $p$ value \\
\hline Time since installation & 1,536 & 46.56 & 0.0001 \\
Decoy origin & 1,305 & 3.54 & 0.061 \\
Time $\times$ decoy origin & 1,536 & 4.74 & 0.030 \\
\hline
\end{tabular}

Area, block, and trap location are controlled as random variables

released in the capture site. Trap selectivity was defined as the proportion of captured magpies in relation to the total number (target and non-target) of captured animals (International Organization for Standardization 1999). The captured magpies were euthanized through an intraperitoneal injection of sodium pentobarbitone ( $200 \mathrm{mg} / \mathrm{ml}$ Dolethal Vetoquinol), as recommended for birds (Close et al. 1997). Data from necropsy of captured magpies (age, gender, and physical condition) were used for further studies (authors, in preparation). Some captured magpies were kept alive and used as decoys in further experiments, once sexed through molecular techniques from blood samples (Fridolfsson and Ellegren 1999). Those magpies used as decoys in the same study area where they were captured were considered as "local decoys", whereas those captured elsewhere were considered as "foreign decoys".

Magpie density estimation

The density of magpies in both study areas was estimated with the distance-sampling method (Burnham et al. 1980), which has been successfully employed to estimate the density of a number of bird species, including magpies (Newson et al. 2008). We employed the Fourier series estimator as detection function. Surveys were carried out once a week during the trapping period, following a fixed route $(21 \mathrm{~km}$ in Area 1 and $12 \mathrm{~km}$ in Area 2) with high visibility, starting $2 \mathrm{~h}$ after sunrise. We indirectly assessed the effect of magpie removal on population density (experiment 1 and 2, in study area 1 and experiment 4 in study area 2) by relating the changes in the density of magpies with the number of animals captured in our cagetraps. Raptor and corvid species observed during line transects were recorded in order to assess the abundance
Table 3 Number of magpies captured, trapping effort, and average capture rate during spring and autumn in each study site

\begin{tabular}{llllll}
\hline Season & Site & Nr magpies captured & Effort (trap-days) & \multicolumn{2}{l}{ Capture rate } \\
\cline { 5 - 6 } & & & & Site & Average \\
\hline \multirow{2}{*}{ Spring } & Area 1 & 105 & 355 & 0.26 & 0.32 \\
& Area 2 & 62 & 168 & 0.37 & \\
\hline
\end{tabular}


Fig. 1 Daily capture rate changes along time since trap installation during spring 2006 (experiment 1 and 2) and autumn 2006 (experiment 3) in area 1

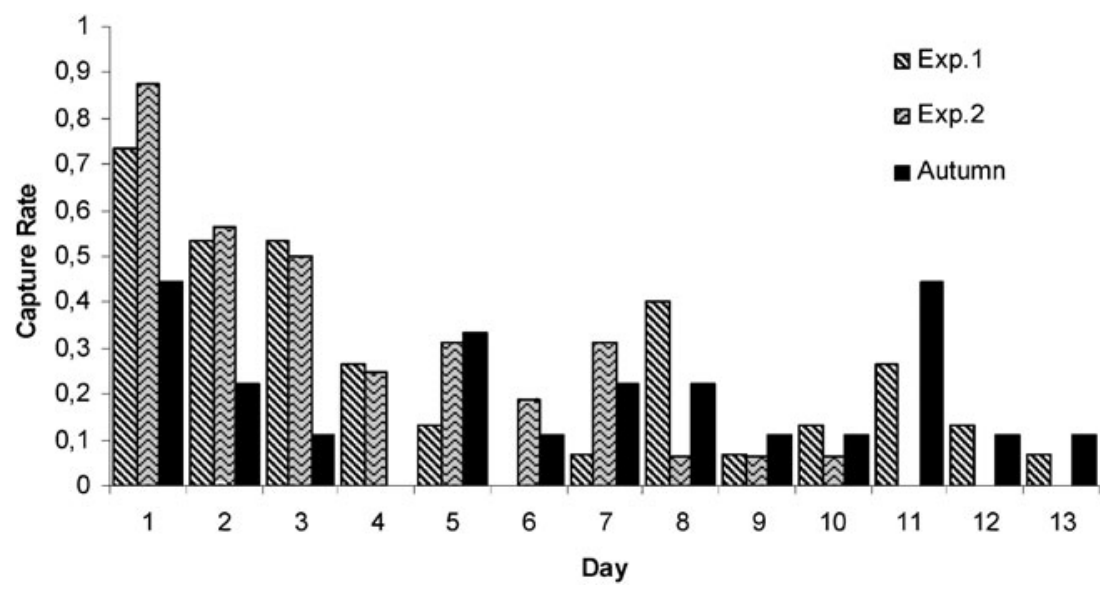

of potential magpie predators or competitors which could enter the traps attracted by the magpie decoy, and related to trap selectivity.

\section{Data analysis}

We first modeled daily capture rate (number of magpies trapped each day that a trap was active) using data from both study areas during spring (experiments 1, 2, and 4). Fixed factors included in this model were: number of days since the trap was installed and decoy origin (local or foreign). Study area, experimental block, and trap location (a categorical variable identifying each trap position) were included as random effects. Trap location was nested within experimental block, because these random effects are not independent. Generalized mixed models with a Poisson error term and a log-link function were used for this and for the remaining analyses of factors affecting capture rate (see below).

Since the amount of time each cage trap was active differed among experiments (see Table 1) and capture rate was significantly affected by time since trap installation (see "Results"), we only considered in further analyses of spring data the captures obtained during the first 5 days

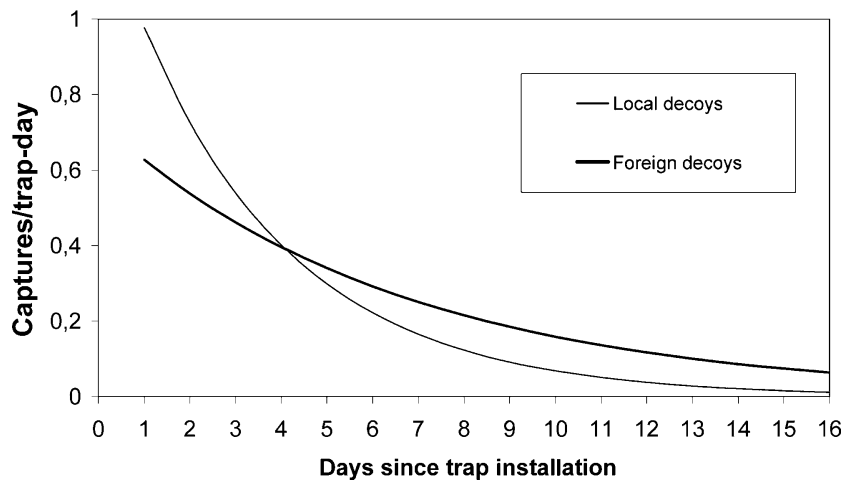

Fig. 2 Expected capture rate as a function of time since trap installation (days) and the origin of the magpie employed as decoy after trap installation, when highest capture rates were obtained (see "Results"). This way, we controlled for experiment duration and did not include this variable in further models of spring data. In order to test for variation in capture rate among experimental treatments, we modeled the number of magpie captures in the first 5 days after trap installation, using data from spring experiments (experiments 1,2 , and 4 ), and the following explanatory factors: trap model (a categorical factor with four levels), type of decoy (female, control-male, and testosterone-male), decoy origin (local or foreign), and study area (1 or 2). Models were fitted to all the data from experiments 1,2 , and 4 . We ranked the obtained models according to their Akaike Information Criterion value (AIC) with respect to the principle of parsimony (Akaike 1973; Burnham and Anderson 1998). The statistical significance of the parameters estimated was assessed using the Wald test.

Finally, the effect of season on capture rate was analyzed including only data from study area 1 , where trapping was performed both in spring (experiments 1 and 2) and in autumn (experiment 3). Since the decay of capture rate along time since trap installation could differ between seasons, we considered the daily capture rate as dependent variable, and fitted generalized linear models to these data, including day since trap installation, season, and their interaction as fixed effects.

\section{Results}

Selectivity

A total effort of 708 trap-days during spring and autumn 2006 produced the capture of 193 magpies and four individuals of non-target species, which indicate a high selectivity of the trapping method $(97.9 \%$ captures of the target species). Non-target captures were common buzzard (Buteo buteo), genet (Genetta genetta), Western hedgehog 
Table 5 Significance of variables used in the mixed models for magpies captured during the 5 days since trap installation

\begin{tabular}{lllr}
\hline Variable & Degr. of freedom & Wald test & $p$ value \\
\hline Intercept & 1 & 0.531 & 0.466 \\
Trap type & 3 & 0.992 & 0.609 \\
Gender and testosterone & 2 & 3.433 & 0.180 \\
Origin & 1 & 2.407 & 0.121 \\
\hline
\end{tabular}

Last column indicates the relative importance of each predictor variable estimated as the sum of the Akaike weights over all the models including each variable

(Erinaceus europaeus), and red-legged partridge. None of these captured animals resulted injured and they were released in the capture site. Despite the low capture rate of non-target species, several medium raptors, potential predators of magpies, were frequently seen in the surroundings $(<100 \mathrm{~m})$ of the traps during the daily checks and during the weekly transects for magpie density estimation (Table 2).

Effect of trapping time on capture rate

Average capture rate during spring was 0.32 magpies/trapdays (see Table 3). We checked for overdispersion in the data, and extra-dispersion scale was close to 1 (0.9), therefore it was not necessary to correct for this factor and the use of Poisson errors was appropriate for modeling capture rates. Capture rate significantly decreased over time since trap installation (Table 4, Fig. 1). Other significant term included in the models was the interaction between time and decoy origin (see Table 4). According to this, local decoys provided higher capture rate than foreign decoys during the first days, but lower during later days (Fig. 2). Study area, block and trap location, included as random terms, did not result significant.

Effects of type of decoy and trap model on capture rate during spring

The following analysis focused on the number of magpies captured during the first 5 days after trap installation, when capture rate is highest in all the experiments (see Figs. 1 and 2). None of the factors considered (trap type, gendertestosterone, and decoy origin) resulted significant in the models (Table 5). However, trap type was included in the five models with lowest AIC and had the highest sum of Akaike weight (Tables 5 and 6). The trap types with four capture chambers tend to have higher capture rates than the model with two capture chambers (Fig. 3).

Effect of season

Average capture rate in study area 1 during autumn (experiment 3) was lower (0.14 magpies/trap-day) than during spring (0.26 magpie/trap-day; see Table 3, Fig. 1). However, only days since trap installation, but not season, resulted significant in generalized models including data from spring and autumn in study area 1 (Table 7).

\section{Effect of captures on magpie density}

Magpie density before the breeding season was estimated as $0.23 \pm 0.06$ magpies/ha in study area 1 and $0.39 \pm 0.09$ magpies/ha in study area 2 . The magpies removal during the breeding season (spring) was followed by a decline in magpie density in both study areas (see Fig. 4). In area 1 the initial density declined coinciding with the first 60 magpies removed. Despite magpie density increased in the fourth census, the density at the end of the trapping season was lower than the initial density (Fig. 4a). After the
Table 6 Summary of mixed models for magpies captured during the 5 days since trap installation

Tr trap type, $D S$ decoy gender and testosterone level, $D O$ decoy origin (variables)

\begin{tabular}{|c|c|c|c|c|c|c|c|}
\hline Model & Variables & Degr. of freedom & AIC & $\Delta \mathrm{AIC}$ & $x^{2}$ & $p$ value & $w_{\mathrm{i}}$ \\
\hline 1 & $\operatorname{Tr}$ & 2 & 172.219 & 0.000 & 3.886 & 0.143 & 0.106 \\
\hline 2 & $\operatorname{Tr}+\mathrm{DO}^{*} \operatorname{Tr}$ & 4 & 172.648 & 0.430 & 7.456 & 0.114 & 0.086 \\
\hline 3 & $\mathrm{DO}$ & 1 & 173.211 & 0.992 & 0.893 & 0.345 & 0.065 \\
\hline 4 & $\mathrm{Tr}+\mathrm{DS}^{*} \mathrm{DO}$ & 4 & 173.508 & 1.289 & 6.597 & 0.159 & 0.056 \\
\hline 5 & $\mathrm{DS} * \mathrm{DO}$ & 2 & 173.587 & 1.368 & 2.518 & 0.284 & 0.054 \\
\hline 6 & $\mathrm{DO}+\mathrm{Tr}$ & 3 & 173.704 & 1.485 & 4.401 & 0.221 & 0.051 \\
\hline 7 & $\mathrm{DO}^{*} \operatorname{Tr}$ & 2 & 173.850 & 1.631 & 2.254 & 0.324 & 0.047 \\
\hline 8 & DS & 2 & 173.926 & 1.707 & 2.178 & 0.336 & 0.045 \\
\hline 9 & $\operatorname{Tr}+\mathrm{DS}^{*} \mathrm{DO}+\mathrm{DO} * \operatorname{Tr}$ & 6 & 174.075 & 1.856 & 10.030 & 0.123 & 0.042 \\
\hline
\end{tabular}




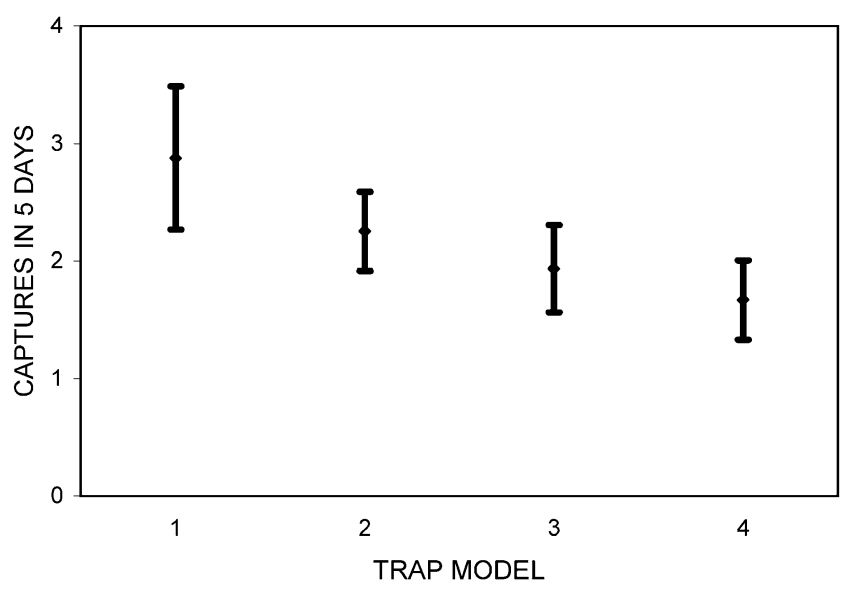

Fig. 3 Average number $( \pm \mathrm{SE})$ of captured magpies per trap during the first 5 days after trap installation according to trap model (1-3 with four capture chambers, 4 with two capture chambers)

trapping ceased, magpie density tended to increase. In area 2 , the effect of trapping is clearer than in area 1 . There, the initial density of magpies was reduced following the trapping season (Fig. 4b), and did not increase after the end of the trapping season.

\section{Discussion}

The tested traps are highly selective for the capture of magpies, according to our results (98\% selectivity). This is not the result of the absence of species susceptible to be captured in the traps. Both systematic and non-systematic surveys indicate that species susceptible to enter the traps are abundant in the study areas (See Table 2). This is the case of magpie predators, such as medium-size raptors, and magpie competitors, such as other corvids (e.g. Jackdaw, Corvus monedula, Högstedt 1980). Only a common buzzard was captured in the traps among the medium-size raptors able to capture magpies that were observed (Accipiter nisus, Circus sp., B. buteo). However, we did not detect in any of the study areas the presence of goshawk (Accipiter gentilis), a reputed magpie predator (Mañosa 1994), which likely would enter the traps. Some small carnivores ( $G$. genetta, Martes foina, Mustela nivalis, and Mustela putorius) which could be attracted by the decoy and captured in these traps, are likely present in the study areas according to distribution atlas (Palomo et al. 2007), although we lack quantitative data on their abundance. However, only a common genet was captured during the study.

The release of non-target animals captured in magpie traps, when used as a management tool, depends totally on the trapper commitment, as it happens with other traps used for predator control (Duarte and Vargas 2001). Because of that, the training and the awareness of the trappers are necessary to guarantee the release of nontarget captures. Traps must be checked daily to prevent long restraint periods which can reduce the animal welfare and eventually cause the death of both target and nontarget species.

The assessed traps resulted highly effective for the capture of magpies during the breeding season, producing an average capture rate of 0.32 magpies/trap and day. The daily capture rate was highest during the first day after trap installation (0.73-0.87 magpies/trap; Fig. 1). These values are much higher than those obtained in 1-day attempts with bal-chatri traps using an adult female as decoy (0.43; Wang and Trost 2000), although other factors such as magpie density could have affected capture rate.

The trap type was included in the best models of capture rate during the first 5 days, although it was not a significant term. In fact, number of capture chambers seems to increase the capture rate (although not significantly), since trap models with four chambers tended to provide more captures than the model with two capture chambers (Fig. 3).

The popular recommendation of using foreign magpies as decoys to increase captures is not supported by our data, since the origin of the decoy seems not to affect the capture rate. In fact, we obtained a similar number of captures when using the first magpie captured as decoy in the trap where it was captured (authors unpublished, data not included). Although both magpie males and females defend territories, this behavior is more conspicuous in males (Baeyens 1981; Birkhead 1991). However, neither the gender of the decoy nor the testosterone level affected significantly the capture rate (Table 5). Therefore, our data do not support the popular assumption about increasing captures by using male decoys from distant populations.

The lower capture rate in autumn compared to spring (Table 3) could be explained, at least partially, by the lower density just before autumn trapping period ( 0.17 and 0.23 magpies/ha, respectively for autumn and spring in study
Table 7 Summary of results of the mixed model of capture rate including time since installation and season (only data from study area 1)

\begin{tabular}{llcll}
\hline Variable & Degr. of freedom & Wald test & $p$ value & $\Sigma w_{\mathrm{i}}$ \\
\hline Intercept & 1 & 0.223 & 0.637 & \\
Season & 1 & 2.194 & 0.139 & 0.378 \\
Time since installation & 1 & 13.017 & 0.0003 & 1.000 \\
Season $\times$ time since installation & 1 & 2.054 & 0.152 & 1.175 \\
\hline
\end{tabular}


area 1). This lower density in autumn is probably a result of the magpies removed during the experimental trapping in spring. Also during autumn and winter, magpies are more sociable and not so aggressive when defending their territory (Eden 1989; Birkhead 1991). This lower territoriality during the non-breeding season can also explain the lower tendency of magpies to enter the traps.

Recent studies show that predator control often do not reduce local predator abundances (Baker and Harris 2006; Beja et al. 2009). However, in our study, there was a strong decline in one area, whereas in the other the pattern was unclear (Fig. 4). In the study area 2, we observed an increase in magpie density 1 week after trapping started, which was followed by a density decrease during the next week (Fig. 4b). In both areas, these density fluctuations are probably due to sampling variability.

In any case, in both study areas trapping was able to reduce magpie density during the breeding season of game species such as red-legged partridge and therefore the potential predation impact upon nests reduced.

\section{Management implications}

The use of non-selective, illegal methods for predator control in Spain is one of the main causes of mortality for many predator species, both mammals and birds, some of them endangered (Villafuerte et al. 1998). Therefore, it is necessary to identify selective methods for predator control to be used as management and conservation tools in particular situations of high abundance of generalist, nonprotected predators. Such is the case of the traps tested in the present study, which have resulted highly selective and efficient. Some recommendations for using this type of traps for managing magpie populations can be drawn from our results. The breeding season is the most appropriate for effectively control magpie populations with these traps, since capture rate is higher in this period, the magpie density of unmanaged populations is lowest just before breeding and easier to be controlled. On the other hand, this period coincides with nesting of most bird species, including red-legged partridges, reducing in this way nest
Fig. 4 Changes in magpie density (magpies/ha \pm SE) along time (dashed line) and accumulated captures during the trapping season (solid line) in study area 1 (a) and study area 2 (b)

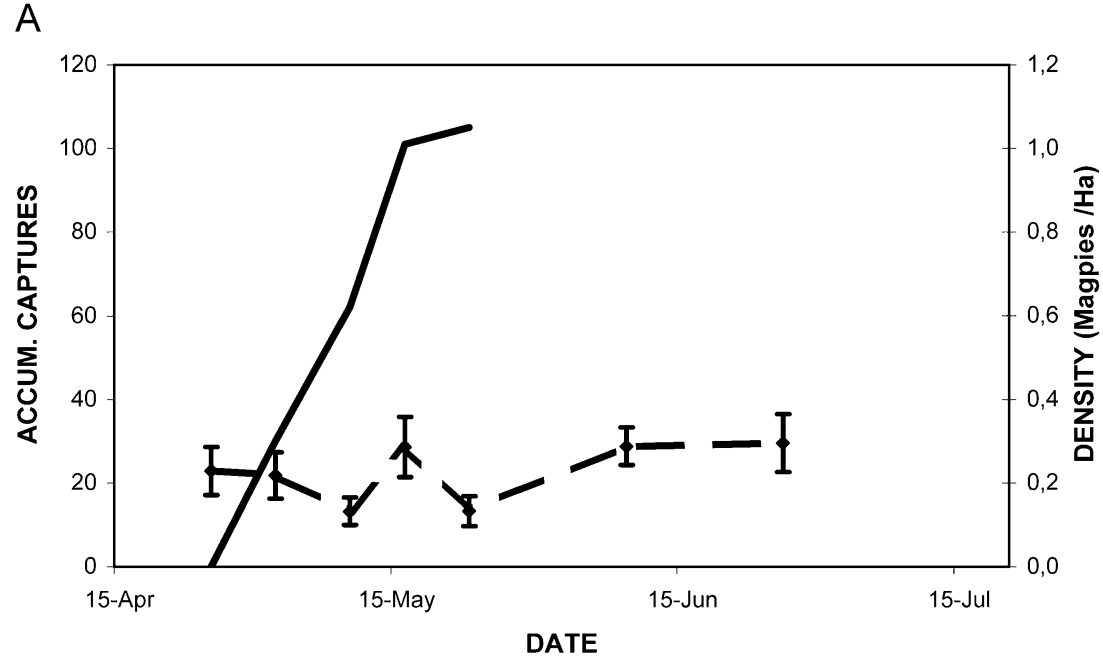

B

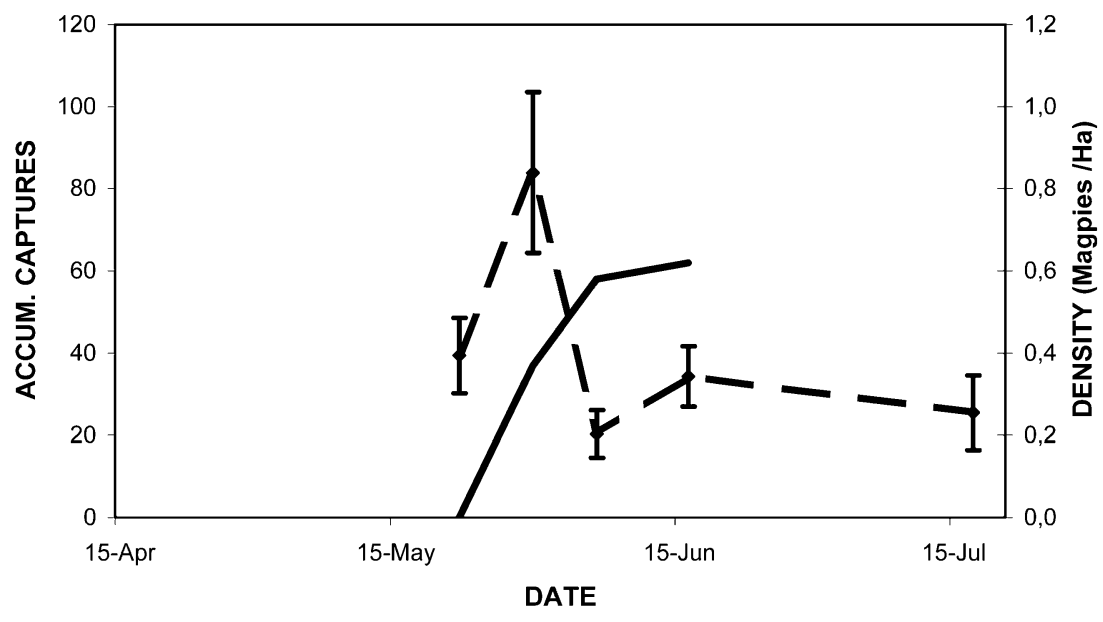


losses due to magpie predation. Traps located in the proximity of magpie nests are highly effective but their efficiency would increase if they are moved to a new location after 4-5 days. Either local or foreign magpies of any gender can be used as decoys in the traps with similar results in capture rate. Traps should be checked daily in order to avoid the reduction of welfare of captures and the personnel in charge of setting and manipulating these traps must be encouraged to liberate individuals of non-target species. Other likely side effects of the traps assessed should be considered before their generalized use. For instance, the effect of the reduction of magpie populations on Great spotted cuckoo populations (Clamator glandarius), a nest parasite specialized on magpie nests (Soler et al. 1996), should be scientifically evaluated and taken into account when authorizing the use of traps for magpie control.
Acknowledgements This study was funded by Consejería de Medio Ambiente of Junta de Comunidades de Castilla-La Mancha (project PREG-05-23). Patrick Fasolo kindly provided the first magpie decoys to start the trapping experiments, and shared with us his long experience with the use of the traps. Land owners and game owners of both study areas facilitated the access to estates and facilitated the field tests. Salvador Luna performed most of the field work. Luis Enrique Mínguez kindly assisted in the field work and solved most bureaucracy during the project development. Beatriz Arroyo provided helpful support with the statistical analyses.

All the experiments comply with the current Spanish laws, and were performed with the corresponding legal authorizations and following current guidelines for animal welfare.

\section{Appendix}

Trap models employed in the experiments: models $1-3$ have four capture chambers (a), whereas model 4 has two capture chambers (b).
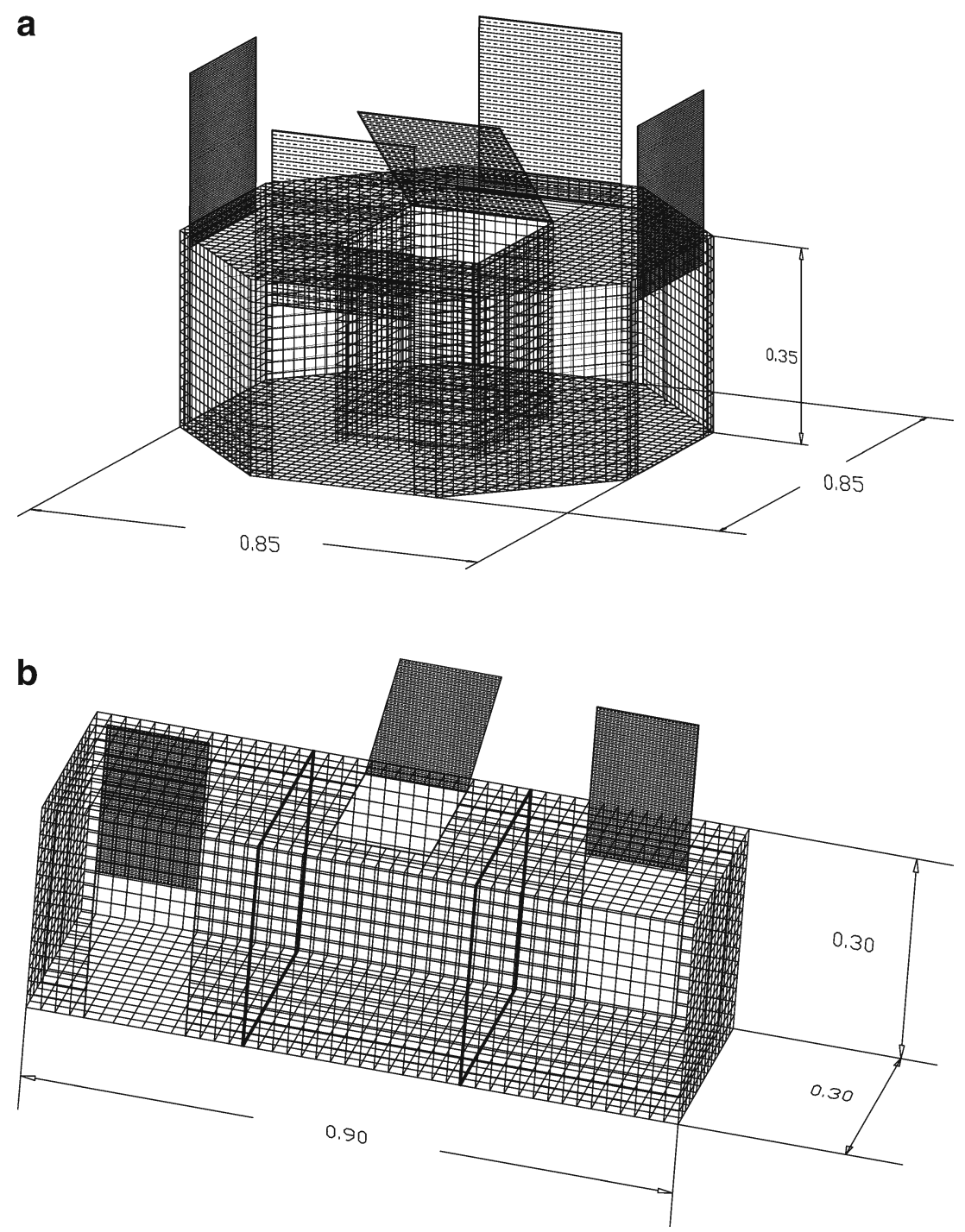


\section{References}

Akaike H (1973) Information theory and an extension of the maximum likelihood principle. In: Petrov BN, Csaki F (eds) 2nd international symposium on information theory. Akademiai Kiado, Budapest, pp 267-281

Baeyens G (1981) The role of the sexes in territory defence in the Magpie (Pica pica). Ardea 69:69-82

Baker PJ, Harris S (2006) Does culling reduce fox (Vulpes vulpes) density in commercial forests in Wales, UK. Eur J Wildl Res 52:99-108

Beja P, Gordinho L, Reino L, Loureiro F, Santos-Reis M, Borralho R (2009) Predator abundance in relation to small game management in southern Portugal: conservation implications. Eur J Wildl Res 55:227-238

Bernabeu RL (2000) Evaluación económica de la caza en Castilla-La Mancha. Ph.D. thesis, University of Castilla-La Mancha

Birkhead TR (1991) The Magpies. The ecology and behaviour of black-billed and yellow-billed Magpies. T \& A D Poyser, London

Blanco-Aguiar JA, García FJ, Ferreras P, Viñuela J, Villafuerte R (2001) Effect of game management on artificial nest predation in central Spain. 25th International Union of Game Biologists (IUGB) and the 9th International Symposium on Perdix. Limasol, Chipre

Blas J, Perez-Rodriguez L, Bortolotti GR, Vinuela J, Marchant TA (2006) Testosterone increases bioavailability of carotenoids: insights into the honesty of sexual signalling. Proc Nat Acad Sci U S A 103:18633-18637

Boza MD (2002) El trampeo y demás artes de caza tradicionales en la Península Ibérica. Editorial Hispano Europea S.A, Barcelona

Burnham KP, Anderson RR (1998) Model selection and inference: a practical information-theoretic approach. Springer, New York

Burnham KP, Anderson RR, Laake JL (1980) Estimation of density from line transect sampling of biological populations. Wildl Monogr 72:1-202

Chiron F, Julliard R (2007) Responses of songbirds to magpie reduction in an urban habitat. J Wildl Manage 71(8):2624-2631

Close B, Banister K, Baumans V, Bernoth EM, Bromage N, Bunyan J, Erhardt W, Flecknell P, Gregory N, Hackbarth H, Morton D, Warwick C (1997) Recommendations for euthanasia of experimental animals: part 2. DGXT of the European Commission. Lab Anim 31:1-32

Delibes-Mateos M (2006) Relaciones entre los cambios poblacionales del conejo, la gestión cinegética, el hábitat y los depredadores: implicaciones para la conservación. Ph.D. thesis, University of Castilla La Mancha

Duarte J, Vargas JM (2001) ¿Son selectivos los controles de predadores en los cotos de caza? Galemys 13:1-9

Eden SF (1989) The social organisation of non-breeding magpies Pica pica. Ibis 131:141-153

Ferreras P, Villafuerte R, Mateo A (2006) Incidencia de la depredación sobre nidos de perdiz roja (Alectoris rufa) en Navarra. Unpublished Final Report. Departamento de Medio Ambiente, Ordenación del Territorio y Vivienda del Gobierno de Navarra and IREC-CSIC

Fridolfsson AK, Ellegren H (1999) A simple and universal method for molecular sexing of non-ratite birds. J Avian Biol 30:116-121

Gooch S, Baillie SR, Birkhead TR (1991) Magpie Pica pica and songbirds populations. Restrospective investigation of trends in population density and breeding success. J Appl Ecol 28 (3):1068-1086
Hernandez M, Margalida A (2009) Poison-related mortality effects in the endangered Egyptian vulture (Neophron percnopterus) population in Spain. Eur J Wildl Res. doi:10.1007/s10344-0090255-6 Published online

Herranz J (2000) Efectos de la depredación y del control de predadores sobre la caza menor en Castilla-La Mancha. Ph.D. thesis, Autónoma University. Madrid

Högstedt G (1980) Prediction and test of the effects of interspecific competition. Nature 283:64-66

International Organization for Standardization (1999) TC191. Animal (mammal) traps. Part 5: methods for testing restraining traps. International Standard ISO/DIS 10990-5. International Organization for Standardization, Geneva, Switzerland

Mañosa S (1994) Goshawk diet in a Mediterranean area of northeastern Spain. J Raptor Res 28:84-92

Martínez JG, Soler M, Soler JJ, Paracuellos M, Sánchez J (1992) Alimentación de los pollos de urraca (Pica pica) en relación con la edad y disponibilidad de presas. Ardeola 39:35-48

Martínez de Castilla A, Martínez A (2004) ¿Es beneficioso controlar las urracas? Trofeo. December 2004:58-62

Newson NE, Evans KL, Noble DG, Greenwood JJD, Gaston KJ (2008) Use of distance sampling to improve estimates of national population sizes for common and widespread breeding birds in the UK. J Appl Ecol 45:1330-1338

Otero C (1995) Control de depredadores en la gestión integrada de un territorio. In: Predación, caza y vida silvestre. Fundación "La Caixa"/Aedos, Barcelona, pp 151-180

Palomo LJ, Gisbert, J, Blanco JC (2007) Atlas y libro rojo de los mamíferos terrestres de España. SECEM-Organismo Autónomo de Parques Nacionales, Ministerio de Medio Ambiente

Potts GR (1980) The effects of modern agriculture, nest predation and game management on the population ecology of partridges (Perdix perdix and Alectoris rufa). Adv Ecol Res 11:2-79

SEO/BIRDLIFE (2002) Tendencias de las poblaciones de aves comunes en España (1996-2001). Programa SACRE. Informe 2001. SEO/BirdLife, Madrid

Sillero-Zubiri C, Laurenson MK (2001) Interactions between carnivores and local communities: conflict or coexistence? In: Gittleman J, Funk K, MacDonald D, Wayne R (eds) Carnivore conservation, conservation biology series 5. Cambridge University Press, Cambridge, pp 282-312

Soler M, Martínez JG, Soler JJ (1996) Effects of brood parasitism by the Great Spotted Cuckoo on the breeding success of the Magpie host: an experimental study. Ardeola 43:87-96

Thirgood SJ, Redpath SM, Newton I, Hudson P (2000) Raptors and red grouse: conservation conflicts and management solutions. Conserv Biol 14:95-104

Thomson DL, Green RE, Gregory RD, Baillie SR (1998) The widespread declines of songbirds in rural Britain do not correlate with the spread of their avian predators. Proc R Soc Lond B 265:2057-2062

Vargas JM (2002) Alerta cinegética. Reflexiones sobre el futuro de la caza en España. Otero Ediciones, Madrid

Villafuerte R, Viñuela J, Blanco JC (1998) Extensive predator persecution caused by population crash in a game species: the case of red kites and rabbits in Spain. Biol Conserv 84:181-188

Wang XH, Trost CH (2000) Trapping territorial black-billed Magpies. J Field Ornithol 71:730-735

Wingfield JC, Ball GF, Dufty AM, Hegner RE, Ramenofsky M (1987) Testosterone and aggression in birds. Am Sci 75:602-608

Yanes M, Herranz J, De la Puente J, Suárez F (1998) La perdiz roja. Identidad de los depredadores e intensidad de la depredación. In: I Curso. La perdiz roja. FEDENCA, Alcobendas, Madrid, pp 135-147 